\title{
Clarice Lispector e Stéphane Mallarmé: a orquestração do rumor
}

Vinícius Pacheco Gonçalves ${ }^{1}$

RESUMO: O presente artigo pretende calcular os contrastes da leitura da segunda versão, datada de 1887, do "Sonnet allégorique de lui-même”, de Stéphane Mallarmé, e do conto "O ovo e a galinha”, de Clarice Lispector. Interessa-nos explorar, no referido corpus, possíveis entre-tons nas leituras já consensuais do legado poético mallarmaico, desenhando na intersecção que os textos em questão conformam uma outra possibilidade de enfrentamento do literário: a de espaço sem lugar, nômade, ou seja, sem contas a pagar aos discursos positivos que configuram objetos estáveis no campo de nossa visão cotidiana. Em suma: flagrar os modos de existência, no espaço artístico da literatura, que a ficcionista brasileira e o poeta francês instauram entre a premência sensata da fala sólida e a potência escura do silêncio. Numa palavra: como ambos habitam esse lusco-fusco; como ambos orquestram o rumor de que suas obras são feitas.

PALAVRAS-CHAVE: Clarice Lispector, Stéphane Mallarmé, espaço sem lugar, rumor.

ABSTRACT: This article intends to show the contrasts in the reading of the second version of "Sonnet allégorique de lui-même”, written by Stéphane Mallarmé, and of the short story "O ovo e a galinha”, by Clarice Lispector. The intention is, first of all, to explore in the aforementioned corpora, possible nuances in the canonical interpretations of the poetic legacy of Mallarmé, drawing, in the point of intersection of the texts, another possibility for the comprehension of the literary: that of a space without a place; a nomadic space, with no debts to the positive speeches which configure stable objects in our ordinary vision. In short: to highlight the modes of existence established, in the artistic space of Literature, by the Brazilian fiction writer and the French poet, between the reasonable urgency of the solid speech and the dark power of silence. In one word: to see how they both live in this twighlight zone; how they both orchestrate the murmur their works are made of.

KEYWORDS: Lispector, Mallarmé, space without a place, murmur.

Ah! Caicó arcaico

Em meu peito catolaico

Tudo é descrença e fé

Ah! Caicó arcaico

Meu texto é mallarmaico

Tudo rejeita e quer

(Chico César)

É possível assinalar semelhanças entre os escritores Stéphane Mallarmé e Clarice Lispector e, ainda que não haja evidências de que esta tenha lido aquele, o cálculo de tais semelhanças se torna pertinente, a nosso ver, diante da atual releitura da porção dita mais "hermética" da obra do poeta francês, do enfrentamento de certa "dificuldade" de sua forma. O que nos interessa aqui é, sobretudo, vislumbrar alguns dos efeitos decorrentes

1 Mestrando em Literatura Francesa pela Universidade de São Paulo - São Paulo.

Contato: vinicius.pacheco.goncalves@usp.br

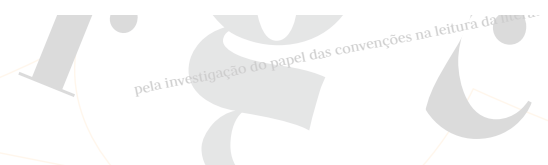


do contato com a ficcionista brasileira na tentativa de adensar a relação que temos com o postulado poético mallarmaico. A ponta do iceberg que deu alento ao presente esforço comparativo se traduz na incorporação da crise da representação literária e na criação de um espaço escritural que não faz referência nem deferência aos poderios discursivos dos domínios dos saberes constituídos. Para dialogarmos com Marcos Siscar:

O poderio econômico é aquele que negocia a realidade por meio de palavras, por meio de uma certa concepção de linguagem, que transforma a linguagem em uma 'universal reportagem'. Desse modo, alienando a linguagem, aliena também o homem de sua divindade. A profanação crítica, no caso, não se baseia em nenhuma nostalgia pré-capitalista de valores não mercantes. No lugar da catedral, como lembra Marchal, Mallarmé sonha com a edificação de um palácio de vidro, baseado no gênio metafórico e aliterativo da língua, instalando o nada no centro do espaço social. (SISCAR, 2010, p. 94-95)

Como um "palácio de vidro" edificado no seio da cidade, a escritura dos dois autores constitui, para nós, mais do que um movimento de resistência política nas entranhas da linguagem: trata-se de uma violência contra os agenciamentos petrificados nas moedas correntes da comunicação humana (as ciências, a publicidade, o jornalismo, enfim, à “universal reportagem”, para usar uma expressão do próprio Mallarmé na prosa crítica de Divagações) e da fulguração da palavra como ser anônimo que se institui como ruína do próprio ser, como quer Peter Pál Pelbart.

O "fundamento" da obra acaba sendo o abismo aterrador com o qual (e contra o qual) ela foi construída, e sobre o qual ela se sustenta por um instante ao menos, na iminência, sempre, de ser engolfada de vez. Forçando um pouco, diríamos que a essência da obra - aquilo que constitui seu "chão", sua "condição", seu "destino", seu movimento mais próprio - é sua ruína. O ser da obra é a ruína do ser. (PELBART, 1989, p.79)

Podemos afirmar desde já que a intersecção que aqui se desenha se dá na postura que os dois autores nos convidam a assumir: estamos diante deles menos como quem tenta remetê-los a uma realidade consignada do que como quem embarca corajosamente no naufrágio de toda realidade "de antemão retombada do mal de alçar o voo", tomando de empréstimo o conhecido verso de Mallarmé em “Um Lance de Dados”. Em suma: como herdeiros de uma sensibilidade construída nas leituras da obra de Clarice, tentaremos lançar entre-tons na recepção do poeta francês.

Para realizar este estudo, escolhemos a versão de 1887 do "Sonnet Allégorique de Lui-Même", que chamaremos doravante "Sonnet en Yx", e o conto "O Ovo e a Galinha", publicado na coletânea Felicidade Clandestina (1971). Analisando e comentando passagens do conto brasileiro e do poema francês, tentaremos evidenciar, pela semelhança de procedimentos formais, a relação vicária entre navegação e naufrágio da e na linguagem, isto é, o modo como os dois autores tornam audível (e visível) a região de silêncio e obscuridade da vida que, no espaço literário, se manifestam como rumor e transição infinita de cores, como pormenorizaremos mais adiante.
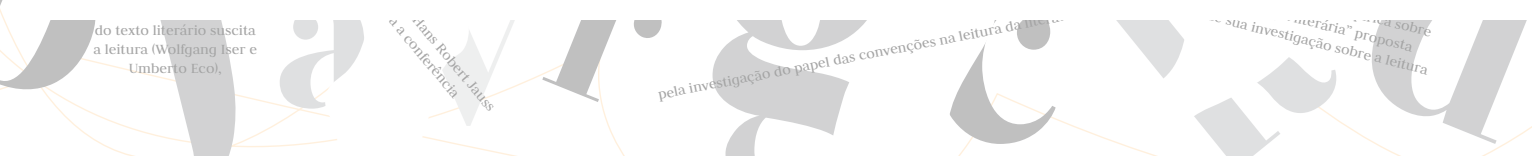


\section{Um ovo cego}

“De manhã na cozinha sobre a mesa vejo o ovo" (LISPECTOR, 1998, p.49)². É com essa frase que se inicia a narrativa clariceana cujo título reutiliza um dos bordões mais famosos a respeito dos mistérios do princípio de causalidade socrático-platônico-aristotélico de que a razão clássica é tributária: distendidos no tempo cronológico, o ovo é a origem da galinha, que, por sua vez, é a condição de existência primária dele mesmo; sendo assim, quem botou e chocou o primeiro ovo do mundo? Com esse questionamento aparentemente brincalhão do senso comum que o título faz lembrar é que a narradora-personagem anuncia a precariedade desse instrumento racional, manifestado no olhar penoso, em crise com a coisa vista, que se ensaiará ao longo do texto.

Da consciência inquietante dessa precariedade do que é visível, buscando ultrapassar as condições de luz que conformam o olhar cotidiano e viciado, é que o narrador tece essa meditação visual, lançando-se na imensidão do ovo como um navegador que se recusasse a tapar as orelhas diante do perigo. "Só vê o ovo quem já o tiver visto. Ao ver o ovo é tarde demais: ovo visto, ovo perdido. Ver o ovo é a promessa de um dia chegar a ver o ovo" (p. 49). Como se percebe nesse trecho, é o enunciado habitual sobre o objeto meditado que calcifica as possibilidades do olhar e que, por extensão, delimita o campo de ação do sujeito que olha. "O ovo não tem um si-mesmo. Individualmente, ele não existe" (p. 49). Não se trata, pois, de buscar uma verdade filosófica oclusa acerca do ovo, que não nos é dado a ver como objeto passível de definição nem como sujeito identificável: são os expedientes da linguagem daquele que conta o conto que não são mais suficientes e que, no entanto, se revezam diante da premência do próprio gesto de contar o ovo, esse eterno desconhecido, essa "exteriorização invisível”: "A relação com o neutro entendido como o desconhecido, com o neutro enquanto desconhecido, significa que esse desconhecido não pode vir à luz pois pertence a uma região estranha à visibilidade, sem que no entanto seja completamente invisível" (PELBART, 1989, p.96).

As cascas do ovo não interiorizam um significado final em estado de gema: elas são o invólucro do próprio silêncio que não pode ser comido pelo sujeito, ou seja, assimilado pelos sistemas de representação de que ele dispõe, tamanha é a potência da vida no espaço que a literatura institui. É, nessas vias, entre a recalcitrância da palavra óbvia, utensílio dos enunciados compartilhados entre os homens que dão ao real alguma visibilidade, e a intransigência do silêncio, trepidação criativa da vida que se funda nas artes, que o texto acaba por orquestrar uma espécie de rumor que se canta da primeira à última linha: "Quando eu era antiga fui depositária do ovo e caminhei de leve para não entornar o silêncio do ovo. Quando morri, tiraram de mim o ovo com cuidado. Ainda estava vivo. - Só quem visse o mundo veria o ovo. Como o mundo, ovo é óbvio" (p. 49-50).

"Mas dedicar-me à visão do ovo seria morrer para a vida mundana, e eu preciso da gema e da clara" (p. 50). Lidar com esse rumor, como se nota agora, exige ainda que o sujeito se livre das camadas que compõem seu nome, seu ego, seu eu-civil, sua intimidade, enfim, sua vida humana. Estamos aqui às voltas com uma espécie de

Para facilitar a leitura, a partir de agora as citações do conto “O Ovo e a Galinha" estarão acompanhadas apenas do número de página - o recurso será usado apenas para as citações de Clarice Lispector.

anti-escultura: a narradora tenta circunscrever a experiência da visão não mundana do ovo, essa coisa incômoda que não é figurável e com a qual só podemos flertar como adivinhos pela aceitação do fracasso da própria linguagem.

Quando a obra literária atinge uma região fora do ser e do não ser do mundo (região esta que, no entanto, não constitui um além-mundo, mas antes um outro do mundo, um ultra-mundo); quando sua essência falha como dado pré-existente é que ela, paradoxalmente, obtém o que não conseguiu, fulgurando eternamente outra no espaço em que aquilo de que fala desapareceu. É o que Maurice Blanchot, novamente de acordo com Peter Pál Pelbart, chama de "a outra noite", cintilação noturna em que a obra de literatura se livra de toda subordinação que a reenvie a uma pessoa, a um lugar, a uma possibilidade, ou melhor, a uma similitude com o que é possível. Errância desse espaço puro sem lugar:

\footnotetext{
Paradoxo: nós costumamos associar o repouso ao 'lugar' - um lugar na vida, na profissão, na estrutura familiar, um lugar na praia, numa casa de campo, um lugar ao sol... E Barthes nos diz justo o contrário: o império dos lugares cansa. Ao invés dos lugares, o espaço. O neutro representa o recuo dos lugares em direção ao espaço - com tudo o que isso implica em termos de possibilidade de circulação, estados intensivos e uma nova modalidade de experiência nômade. Nela prima o indefinido, o indeterminado, a deriva, a errância, a perda etc. (PELBART, 1989, p. 91)
}

Realização do irrealizável, do impossível, a imagem desse ovo que não pode ser visto e representado pelo pensamento (com que frigimos ovos na frigideira do dia-a-dia) escorre gosmenta ameaçando nossos mais humanos asseios: "Em relação ao ovo, o perigo é que se descubra o que se poderia chamar de beleza, isto é, sua veracidade. A veracidade do ovo não é verossímil" (p. 51-52).

Esse luminoso ovo clariceano não é sujeito nem objeto de conhecimento: ele é o próprio desconhecido. Contudo, não se trata de um desconhecido cujo conhecimento esteja por vir por uma suposta ordem evolutiva dos estratos da razão humana; tampouco poderíamos dizer que ele constitui uma categoria incognoscível e transcendente da existência. Sua afirmação linguística só é possível se ele se mantiver como tal: inominável, já que todo nome nele cabe e se esvai. “Ovo visto, ovo perdido" (p. 49): por não possuir uma substância, toda tentativa de substantivação distancia o narrador da nudez e da brancura que ele persegue de modo agônico: "a metamorfose está se fazendo em mim: começo a não poder mais enxergar o ovo" (p. 54).

Adentrar a cegueira que o ovo exige para ser enxergado representa, no entanto, um perigo para a sobrevivência da narradora porque pressuporia a coragem do mais solitário dos atos humanos que confina com as raias da loucura e da inumanidade: "Chamar de branco aquilo que é branco pode destruir a humanidade" (p. 51). Como se vê, a vida coloca em risco a sobrevivência e a tranquilidade do ser: "O desarvoramento da galinha vem disso: gostar não fazia parte de nascer. Gostar de estar vivo dói” (p. 52).

É, portanto, no intervalo entre essa coragem de caminhar com as palavras e a potência desleal do silêncio que a narradora em questão faz do seu monólogo, retomando a expressão citada acima, uma orquestração do rumor. Nesse especial, o percurso
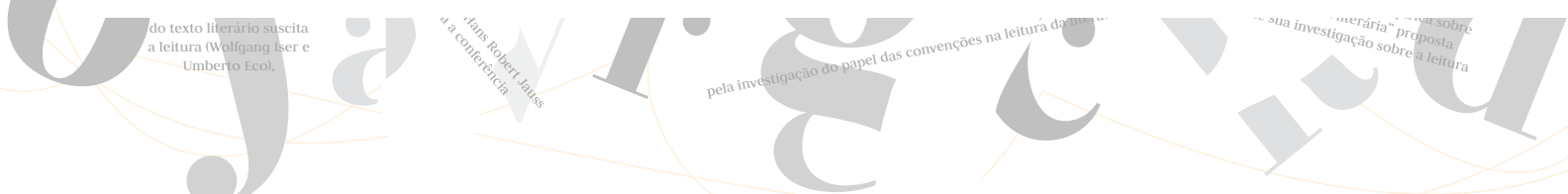
formal que vale a pena registrar aqui é o da inconstância dos significantes utilizados para fixar o ovo, já que todos eles se tornam escorregadios, afinal, "o ovo é um esquivo" (p. 59). Como atributo do sujeito do verbo ser, o ovo é: "a promessa de um dia chegar a ver o ovo"; "supersensível como há sons supersônicos"; "óbvio"; "branco mesmo"; "uma coisa suspensa"; "uma exteriorização"; "a alma da galinha"; "ovo no espaço"; "um dom"; "invisível a olho nu"; "basicamente um jarro?”; "originário da Macedônia”; "coisa que precisa tomar cuidado"; "sempre revolucionário"; "o grande sacrifício da galinha"; "a cruz que a galinha carrega na vida"; e "o sonho inatingível da galinha” (LISPECTOR, 1998, p. 49-52). Nenhum desses atributos é capaz de alcançar o ovo; no entanto, o movimento que todos eles perfazem, como saldo final da narrativa, nos dá o "alcançável", esse rumorejar que rejeita e quer todas as definições, que está constantemente em devir, como a música das sereias que se origina na zona de sua própria desaparição endossando a imagem com que Maurice Blanchot inicia $O$ livro por vir:

As Sereias: consta que elas cantavam, mas de uma maneira que não satisfazia, que apenas dava a entender em que direção se abriam as verdadeiras fontes e a verdadeira felicidade do canto. Entretanto, por seus cantos imperfeitos, que não passavam de um canto ainda por vir, conduziam o navegante em direção àquele espaço onde o cantar começava de fato. Elas não o enganavam, portanto, o levavam realmente ao objetivo. Mas, tendo atingido o objetivo, o que acontecia? o que era esse lugar? Era aquele onde só se podia desaparecer, porque a música, naquela região de fonte e origem, tinha também desaparecido, mais completamente do que em qualquer outro lugar do mundo; mar onde, com orelhas tapadas, soçobravam os vivos e onde as Sereias, como prova de sua boa vontade, acabaram desaparecendo elas mesmas. (BLANCHOT, 2005, p. 3)

"Comecei a falar da galinha e há muito já não estou falando mais da galinha. Mas ainda estou falando do ovo." (p.55) À força de repetir como um mantra a palavra ovo, ela se esvazia: despida do conceito habitual que esse referente carrega, o processo de "sémiosis" - dado que a relação linguística não se estabelece entre a palavra e a coisa, mas entre "entre um signo e outro, um texto e outro texto" (COMPAGNON, 2002, p. 109) - da narrativa o transforma em uma exterioridade pura, isto é, numa superfície absoluta cuja potência consiste em fazer surgir no espaço literário acontecimentos que não são da ordem do vislumbrável e do intuível do ponto de vista da tessitura dos discursos dos saberes que ajuízam e arregimentam o campo de nossa visão cotidiana. Em outros termos: o ovo não é a potência de um significado esfíngico perdido no mapa, cioso de um aventureiro que o busque e o decifre; mas sim uma estratégia de violência criativa que não imita o mundo tal como o conhecemos, que ataca os poderes do óbvio e do lógico, e que choca, no ninho da linguagem, "a iminência incessante pela qual a vida dura desejando" (PELBART, 1989, p. 80-81). Afinal, "O ovo vive foragido por estar sempre adiantado demais para a sua época. - Ovo por enquanto será sempre revolucionário. Ele vive dentro da galinha para que não o chamem de branco" (p. 51).

Visão cegante, ultra-visão que se firma na obscuridade e tira suas forças dela, contemplando, no espaço artístico da literatura, o oco de onde a fala se protela e se projeta
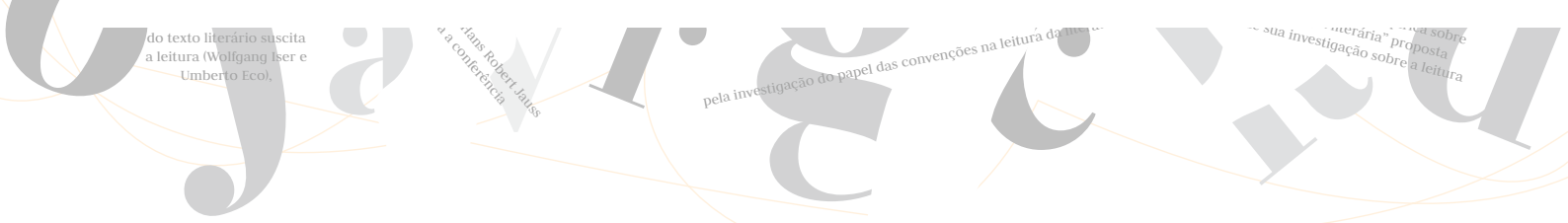
como rumor. Como bem testifica a narradora-personagem de A Paixão Segundo G.H na passagem que abaixo transcrevemos, o fracasso da linguagem diante do que não pode ser dito é, cobra urobórica, sua condição de vitória:

Eu tenho à medida que designo - e este é o esplendor de se ter uma linguagem. Mas eu tenho muito mais à medida que não consigo designar. A realidade é a matéria-prima, a linguagem é o modo como vou buscá-la - e como não acho. Mas é do buscar e não achar que nasce o que eu não conhecia, e que instantaneamente reconheço. A linguagem é o meu esforço humano. Por destino tenho que ir buscar e por destino volto com as mãos vazias. Mas - volto com o indizível. O indizível só me poderá ser dado através do fracasso de minha linguagem. Só quando falha a construção, é que obtenho o que ela não conseguiu. (LISPECTOR, 1998, p. 176)

\section{O nada sonoro}

Alinhavando o que foi chamado anteriormente como a "orquestração do rumor" no conto de Clarice, pretendemos iniciar a análise comentada do Sonnet en Yx de Mallarmé. Nesse poema, veremos o modo como o eu-lírico, mergulhado no que o próprio nomeava como sendo a "desaparição elocutória do autor", também constrói um reino autônomo em que as palavras não se abrem mais às referências dicionarizadas das enciclopédias do mundo, refletindo-se umas nas outras em um jogo especular infinito e infinitivo, vibrando através da força que as fez desaparecer na "outra noite" (retomando o conceito acima utilizado). Endossando a posição de Blanchot sobre tal desaparição: "Mas há outro nível em que a afirmação do livro sem autor toma um sentido muito diferente e, a meu ver, muito mais importante. 'A obra implica o desaparecimento elocutório do poeta, que cede a iniciativa às palavras, mobilizadas pelo choque de sua desigualdade...”" (BLANCHOT, 2005, p. 334).

Assim como o mantra visual clariceano, com todas as suas malogradas tentativas gramaticais de enxergar o ovo, essa instância inelutável do neutro ${ }^{3}$; o empreendimento mallarmaico descreve uma trajetória musical pautada no silêncio e no abismo do espaço de "mobilidade pura" que é o texto literário: "A poesia se torna então o que seria a música, se reduzida à sua essência silenciosa: um andamento e um desdobramento de puras relações, isto é, mobilidade pura" (BLANCHOT, 2005, p. 330). A seguir o soneto sobre o qual trataremos:

\footnotetext{
Ses purs ongles très haut dédiant leur onyx,

L'Angoisse, ce minuit, soutient, lampadophore,

Maint rêve vespéral brûlé par le Phénix

Que ne recueille pas de cinéraire amphore
}

Sur les crédences, au salon vide: nul ptyx,

Aboli bibelot d'inanité sonore,

Ainda segundo Pelbart (1989), a principal característica do neutro é o seu caráter intrinsecamente atópico. Ele não é nem da ordem do ser nem do objeto, já que só pode ser considerado objeto o que tem lugar detectável no interior de um campo.




(Car le Maître est aller puiser des pleurs au Styx

Avec ce seul objet dont le Néant s’honore).

Mais proche la croisée au nord vacante, un or

Agonise selon peut-être le décor

Des licornes ruant du feu contre une nixe,

Elle, défunte nue en le miroir, encor

Que, dans l'oubli fermé par le cadre, se fixe

De scintillations sitôt le septuor.

(MALLARMÉ apud CAMPOS, 1974)

Primeiramente, é preciso fazer algumas observações sobre a organização do poema: trata-se de dois quartetos e dois tercetos que não foram construídos através do esquema da tradição: Mallarmé toma a rima feminina da masculina e a masculina da feminina, como se uma fosse o reflexo da outra (os quartetos: "yx" e "ore"; os tercetos: "or" e "ixe"; a forma utilizada é " $\mathrm{ABAB}$ : $\mathrm{ABAB} / \mathrm{CCD}$ : $\mathrm{CDC}$ ”). O poema apresenta também duas frases que o constituem: uma que se estende nos quartetos e outra nos tercetos, o que se opõe à tendência francesa de organização silogística dos sonetos (exposição, negação, crise e desfecho). O poeta reaproveita as técnicas da tradição poética, modificando-lhes algumas feições, já que a matéria de que trata exige essa "modulação" de sua voz:

Une haute liberté d'acquise, la plus neuve: je ne vois, et ce reste mon intense opinion, effacement de rien qui ait été beau dans le passé,je demeure convaincu que dans les occasions amples on obéira toujours à la tradition solennelle, dont la prépondérance relève du génie classique: seulement, quand n’y aura pas lieu, à cause d'une sentimentale bouffée ou pour un récit, de déranger les échos vénérables, on regardera à le faire. Toute âme est une mélodie, qu'il s’agit de renouer; et pour cela, sont la flûte ou la viole de chacun.

Selon moi, jaillit tard une condition vraie ou la possibilité, de s'exprimer non seulement, mais de se moduler, à son gré. (MALLARMÉ, 2002, p. 360)

Em seguida, antes de começar a análise detalhada de cada verso, faz-se necessário explicitar a primeira linha de composição do soneto: o esquema do "jogo de espelhos" que podemos notar na declaração a seguir:

J'extrais ce sonnet [...] d'une étude projetée sur la parole: il est inverse, je peux dire que le sens, s'il en a un (mais je me consolerais du contraire grâce à la dose de poésie qu'il renferme, ce me semble) est évoqué par un mirage interne des mots mêmes [...] J’ai pris ce sujet d’un sonnet nul se réfléchissant de toutes les façons [...]. (MALLARMÉ, 2002, p. 1489-1490) 
Encharcado das águas mitológicas de um discurso amnésico ${ }^{4}$, as palavras do poema são totalmente opacas, não possuem um "além", uma dimensão transcendente: o sentido, em relação ao espaço de criação poética, é imanente e intransitivo. Como escreveu o poeta, se houver um sentido, este será "mirage interne" das palavras, ressalvando que "je me consolerais du contraire", ou seja, declara sua intenção em não produzir sentido reconhecível "grâce à la dose de poésie qu'il renferme". Note ainda que a poesia, no comentário do autor, se harmoniza com a noção, no presente estudo mobilizada, de espaço puro e sem lugar, espaço da "outra noite". Assim como o ovo de Clarice que "não tem um si-mesmo" e "individualmente não existe" (ou seja, desconhecido porque não é passível de conhecimento), o jogo de espelhos do soneto em questão não tem em perspectiva a imagem primeira que desencadeou sua ação.

Como o título da primeira versão de 1868 do poema sugere, "Sonnet Allégorique de Lui-Même", o objeto, por assim dizer, de que trata o texto é reflexo puro de si mesmo, não pertencendo à ordem do retratável, como o ovo clariceano: anti-escultura que só poderia constituir uma figura se tomássemos como diapasão a dimensão imanente do próprio texto, esse reino à revelia. Trabalho de alquimista, Midas ao contrário, o poeta e/ou escritor de prosa, cria "des-criando" o que já existe, instituindo no mundo possível mundos invisíveis que com este, paradoxalmente, dialogam em condição de víscera: "A alquimia pretende criar e fazer. A poesia des-cria e institui o reino do que não existe e não pode, designando ao homem como sua vocação suprema algo que não pode ser enunciado em termos de poder" (BLANCHOT, 2005, p. 333).

Nessas vias, vamos ao poema propriamente dito. O particípio presente do primeiro verso do soneto sugere um gesto de oferta quase religioso, uma elevação quase ritualística (vide a reverberação litúrgica da palavra "crédences" na segunda estrofe): "Ses purs ongles três haut dédiant leur onyx". Contudo, o termo "onyx" acaba por remeter às "ongles" a imagem destas: tal gesto dedicatório, no lugar de manifestar a ação de oferta absoluta sugerida, não se refere senão a si mesmo. As três outras rimas da estrofe, "lampadophore", "Phénix", sendo palavras de origem grega, nos incitam a tomar "onyx" na acepção grega também: em grego, "onyx" designa a matéria das unhas, de modo que, primeiro reflexo do jogo acima referido, "ongles" e "onyx" se refletem mutuamente. A partir do segundo verso, a "Angoisse" (personificada com uma maiúscula) sustenta o "revê vespéral": trata-se de uma luz que se apaga na aparição do sol negro. Ao fim do terceiro verso, vale notar que, ainda que a "Phénix" seja o pássaro que renasce de suas cinzas, nesse soneto não é ela quem é queimada: ao contrário, é ela aquela que queima: a luz queima dia a dia os sonhos da noite. Outro reflexo recíproco: a expressão "cinéraire amphore" convoca imediatamente a imagem precedente da "Phénix": esse recipiente luminoso e funerário é o receptáculo perfeito que recolhe o sol morto, o "rêve vespéral" queimado pela "Phénix”. No fim da estrofe, do "rêve vespéral brûlé", não resta nada: nenhuma "cinéraire amphore" pode recolher as cinzas.

De acordo com Bertrand Marchal no ensaio Ses purs ongles (1985), é necessário que a linguagem se esqueça como linguagem para adquirir caráter mítico. E toda divindade não é nada senão uma palavra que perdeu sua memória etimológica. 
Na segunda estrofe, podemos ler imediatamente uma palavra estranha: o "ptyx". "Ptyx" é, antes de mais nada, a palavra que por excelência não designa nada, que só possui realidade como som: "l'aboli bibelot d’inanité sonore" de que o próximo verso (um aposto) fala. O "ptyx" é o signo do poema, sua "mise en abyme", nenhum ptyx enuncia a ausência de um poema que diz sua própria ausência, transubstanciando-a (e aqui cabe mais uma vez a supracitada imagem do Midas ao contrário) em aparição poética: como o algarismo zero que é signo da própria falta ou como "o ovo" que é "a promessa de um dia ver o ovo", o poema é "nul” porque é o gesto de que o "Néant s’honore" (que também, nesse caso, poderia ser lido como "néant sonore").

Apesar da possibilidade de lermos essa palavra em sua origem grega (lá ela designa uma "conque", uma concha do mar), a expressão nos serve aqui para reforçar novamente o acima referido depoimento de Mallarmé: "un sonnet nul se réfléchissant de toutes les façons". O segundo quarteto acaba com os parênteses que suscitam a existência de um "Maître" que "est allé puiser des pleurs au Styx": o "Maître" se dirigiu ao rio da morte como um novo Orfeu que, por falta da lira mágica, tem como único recurso o "ptyx" (uma vez que o "seul objet dont le Néant s'honore corresponde ao "ptyx", instrumento “d’inanité sonore", poema "cinéraire"). Nessas vias, a esse novo Orfeu que brota do poema só é concedido "puiser des pleurs" por causa de uma Eurídice perdida para sempre. Tal busca órfica da ausente, fadada ao fracasso-vitória da poesia, pode ser entendida de novo como "mise en abyme" do poema diante da sua aspiração ao "Néant": o poeta desce aos infernos do nada absoluto, o "salon vide" do quinto verso, para fazer cantar desse espaço obscuro sua infigurável musa, sua "Beatriz":

\footnotetext{
Limitando-me aqui a alguns pontos de referência, quero somente lembrar que as relações de Mallarmé com o acaso são dadas num duplo encaminhamento: por um lado, é a busca de uma obra necessária que o orienta para uma poesia de ausência e de negação, em que nada de anedótico, nem de real, nem de fortuito deve ter lugar. Mas, por outro lado, dessas poderosas negativas, que agem também na linguagem e que ele só parece usar para chegar, rasurando o que é vivo, a uma fala rigorosa, sabemos que faz uma experiência direta, de uma importância essencial, experiência que poderíamos chamar de imediata, se precisamente o imediato não fosse 'imediatamente' negado nessa experiência. Lembremos somente a declaração de 1867, a Lefébure: “Criei minha obra somente por eliminação, e toda verdade adquirida nascia somente da perda de uma impressão que, tendo cintilado, tinha-se consumado e me permitia, graças às suas trevas dissolvidas, avançar mais profundamente na sensação das Trevas Absolutas. A Destruição foi minha Beatriz”. (BLANCHOT, 2005, p. 330)
}

A busca do descontínuo, do indeterminado, enfim, a tentativa de vencer o acaso culmina na aceitação do rumor, diante do qual o poeta cria "des-criando", ou seja, faz desse rumor, com uma boa dose de violência inventiva, mítica orquestração. Nesse ponto da análise, podemos estabelecer mais uma semelhança com o conto de Clarice: "O que eu não sei do ovo é o que realmente importa. O que eu não sei do ovo me dá o ovo propriamente dito - A Lua é habitada por ovos." A coisa de que a narradora fala, que não possui um "si-mesmo" (e, por isso, não pode ser compreendida), só pode constituir fala se aceitarmos
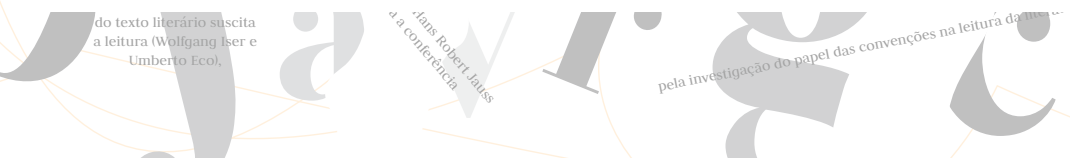
de antemão que o que não se sabe dela é o que a faz reluzir no espaço textual da literatura, que, como anteriormente dito, não se subordina aos liames dos discursos racionais que decompõem, explicam e configuram objetos estáveis no mundo cotidiano.

A fala só se firma, pois, como rumor. A instabilidade rumorejante da narrativa do ovo ("o ovo é uma coisa suspensa") e do sonnet en yx ("seul objet dont le néant s'honore") compõem a grandeza do literário que se presta a transtornar as compreensões esclerosadas da realidade, ou seja, potencializar esta última e instituir nela acontecimentos textuais que transcendem o ruir do tempo cronológico (por não integrar um "lugar") e persistem, já que não se fixam definitivos, no que poderíamos chamar de beleza. No soneto mallarmaico, o canto se alimenta de sua "inanité sonore"; no conto clariceano, "Por devoção ao ovo, eu o esqueci. Meu necessário esquecimento. Meu interesseiro esquecimento. Pois o ovo é um esquivo" (LISPECTOR, 1998, p. 59).

Na terceira estrofe, além do surgimento da "croisée au nord vacante", estamos diante do combate amoroso do "licorne ${ }^{\overline{ }}$ " e da "nixe 6 ", o qual provoca geneticamente a aparição e a fixação do "septuor" estelar na última estrofe. Finalmente, diante da janela aberta ("au nord vacante"), o espelho em que se mira a "défunte nue" reflete não somente o luar de ouro que vem dos "licornes", mas também as estrelas da noite, as estrelas da Ursa Maior: "des scintillations sitôt le septuor". Se é verdade que esse espelho reflete a constelação, é preciso, então, visualizá-lo duas vezes: no céu e no espelho. Dessa maneira, vemos quatorze estrelas, duas vezes o "septuor": exatamente o número de versos que compõem o soneto: quatorze versos que se espelham uns nos outros.

Daí o nome da primeira versão, "Sonnet Allégorique de Lui-Même". Quanto à "défunte nue", trata-se de um aposto de "Elle", que substitui a "nixe" sobre a qual se escoicearam as flamas dos "licornes": uma vez mais, as palavras se dobram sobre si mesmas: "défunte nue "', eco de "Elle", eco de "nixe". É possível, então, afirmar que, sendo fiel ao fio-condutor do "jogo de espelhos", o "septuor" que o soneto evoca se precipita formalmente nele mesmo, deslocando a referência que temos do "septuor" como constelação para a estrutura física do poema no papel. Rasurando o que é visível e desenhando poeticamente uma realidade tão "esquiva" quanto o ovo clariceano, esses efeitos de eco integram os expedientes formais mallarmaicos que corroboram a resistência que o texto literário sustenta contra uma significação positiva do que fala e de uma fala que se ergue à medida que incorpora em si a sua falha; da falha da fala, o "rumor" que vem costurando este estudo. Ou, se quisermos parafrasear uma imagem do próprio Mallarmé, em vez de rumor, estamos lidando com palavras que são tão elas que não têm mais uma cor própria e que são somente transições de uma gama:

Segundo Jean Chevalier e Alain Gheerbrant no Dictionnaire des symboles (1982), "la licorne médiévale est un symbole de puissance, qu'exprime essentiellement la corne, mais aussi de faste et de pureté”.

${ }^{6}$ De acordo com Egerton Sykes no seu Dictionary of non-classical mythology (1953), "in Teutonic myth the priestesses of the lakes, rivers, and wells were known by this name".

${ }^{7}$ Como diria Jean-Pierre Richard, em L'univers imaginaire de Mallarmé (1962), a ninfa do espelho pode ser lida como sendo Calisto, aquela que foi caçada do coro de Artemis, transformada em Ursa Maior e colocada no céu por Júpiter. 
le hasard n'entame pas un vers, c'est la grande chose. Nous avons, plusieurs, atteint cela, et je crois que, les lignes si parfaitement délimitées, ce à quoi nous devons viser surtout et que, dans le poème, les mots - qui déjà sont assez eux pour ne plus recevoir d'impressions du dehors - se reflètent les uns sur les autres jusqu à paraître ne plus avoir leur couleur propre, mais n'être que les transitions d'une gamme. (MALLARMÉ apud, MONDOR, 1943, p. 227)

"Transitions d’une gamme" é também a imagem com que poderíamos vestir o empreendimento gramatical do olhar da narradora do conto de Clarice em direção ao ovo: todos os termos designativos do ovo que elencamos anteriormenteespocam e desaparecem sem deixar rastros de suas cores. "O ovo é uma exteriorização. Ter uma casca é dar-se." (LISPECTOR, 1998, p. 50). Definir o ovo é torná-lo exterior, isto é, visível aos olhos de um outro para quem ele é dado como gesto da própria voz que o comunica na narrativa. Definir é dar uma cor que, diante da incomensurabilidade do que "não sei do ovo" (LISPECTOR, 1998, p.50), é sempre insuficiente.

Dessa pintura que reluta em se tornar visível, temos também, vendo o conto com olhos mallarmaicos, a "transition d’une gamme" que não se aquieta nunca. É, portanto, no percurso transcorrido como um todo pelo monólogo da narradora, que podemos entrever não um significado, mas uma direção que aponta para a impossibilidade do contato com essa zona do "neutro", da "outra noite", do "desconhecido" que não se faça através da "mobilidade pura". Esse canto sirênico, que desponta das entranhas do abismo da linguagem e que compõe nela e através dela o "rumor", é também o entrelugar em que se dá a morte do possível e do reconhecível. Tal intervalo, ao mesmo tempo, instaura um espaço em que o irrealizável, o "supervisível" ganha legitimidade de evidência, de força intransitiva e, nesse decorrer, de intervenção, na margem de circulação ainda concedida ao imaginário da arte, entre os outros textos que integram o emaranhado de verdades (na verdade, ficções que querem ocupar "lugares", retomando agora a distinção entre este termo e o que designa "espaço" na nossa análise) que lastreiam a nossa vista da beleza branca do mundo que, não fosse a literatura, estaria fadada a possuir ou não possuir uma determinada cor. Sobre essa brancura, ainda vale transpormos aqui outro escrito de Mallarmé:

Appuyer, selon la page, au blanc, qui l'inaugure son ingénuité, à soi, oublieuse même du titre qui parlerait trop haut: et quand s'aligne, dans une brisure, la moindre, disséminé, le hasard vaincu mot par mot, indéfectiblement le blanc revient, tout à l'heure gratuit, certain maintenant, pour conclure que rien au-delà et authentiquer le silence. (MALLARMÉ, 2002, p. 387)

"Le hasard vaincu mot par mot": vencer o acaso palavra por palavra só é possível se o apoiarmos no branco da página, ou seja, se fizermos dele a força de voo ou, se quisermos reutilizar um clichê, o lance de dados que o atravessará sem, contudo, proclamar sua abolição. Vencer o acaso consiste, pois, em incorporá-lo às palavras em estado de nomadismo perpétuo, já que é estatuto do branco retornar gratuito "pour conclure que
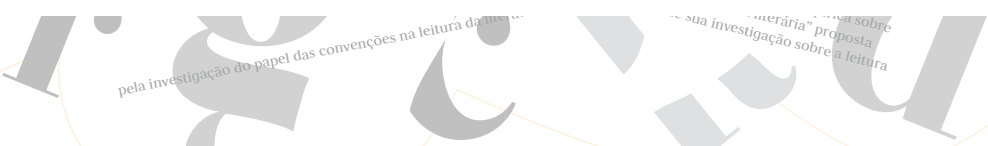
rien au-delà et authentiquer le silence". O espaço literário é nômade porque não assenta raízes axiológicas em lugares institucionais definitivos; porque persiste na brancura que dissolve o nome civil e o perfil psicológico daquele que logrou conjugá-la; porque transcende o tempo profano que a engendrou (esse tempo nosso de calendário distendido em passado, presente e futuro) e que semeou nela a iminência de um sentido histórico sempre em devir, ou seja, provisório como as palavras que nos distanciam e nos aproximam do ovo: “'Falai, falai', instruíram-me eles. E o ovo fica inteiramente protegido por tantas palavras." (LISPECTOR, 1998, p.59).

Transitório como quer a intransitividade da gama de cores da metáfora mallarmaica supracitada. E como quer também este trabalho: como dissemos no início, estabelecer nuances no colorido com que se tem recebido a obra de Mallarmé no Brasil através da(s) sensibilidade(s) que construímos como leitores de Clarice Lispector. Evocando a imagem do disco de Newton, como se viu entre os dois autores, a brancura só é possível como "mobilidade pura" dos seus opostos.

Essa aproximação aparentemente insólita que traçamos entre o conto de Clarice e o soneto de Mallarmé procurou mostrar que ambos instituem um espaço nômade em seus textos que rejeita a fixação a um lugar institucional que os preceda, ocupando, paradoxalmente, na medida em que intervém nos contextos em que são lidos, um contra-ataque aos poderes discursivos (da publicidade, das ciências, do jornalismo etc.) que petrificam a vida no seio da linguagem, fazendo desta um instrumento do óbvio, do reconhecível e do possível. Isso porque o termo "petrificar" significa aqui engessar a única mão de que dispomos; e, por sua vez, a palavra vida, a atitude de violência através da qual podemos manipular, recriar e colocar em movimento não o novo nem o velho, mas o irrealizável e o impossível. Além disso, foi tarefa nossa explicitar como a experiência da palavra anônima navega no naufrágio dos discursos que nega; que não possui um "au-delà"; que é (tantas foram as denominações que utilizamos) orquestração do rumor, a outra noite; enfim, explicitar como essa palavra intransitiva se manifesta no olhar clariceano que se apura na clave da vertigem e no "Néant" mallarmaico, que enfrenta a brancura e a inanição do acaso fazendo deste seu golpe de asa.

No conto $O$ Ovo e a galinha, a tentativa de nitidez do ovo que é também nitidez de si - "O ovo é a alma da galinha" (LISPECTOR, 1998, p. 50) - se faz na tensão com o perigo - "Chamar de branco o que é branco pode destruir a humanidade" (p. 51) - diante do invisível e da cegueira necessária para alcançá-lo; diante disso e da vontade de sobreviver - "Pois parece que viver não existe" (p. 52); "Ovo que se quebra dentro da galinha é como sangue" (p. 53) -, fica-se com o "alcançável", que é o revezamento de todos os significantes que designam o ovo e que se fixa à medida que se esfarela.

No Sonnet en $Y x$, a busca da brancura e do silêncio ("seul objet dont le Néant s'honore") se traduz em criação de suas condições de enunciabilidade: música, que é também transição infinita e infinitiva da gama de cores que maculam o branco. Para escrever esse branco, seja no abismo de espelhos em yx, seja na fragilidade mortal do
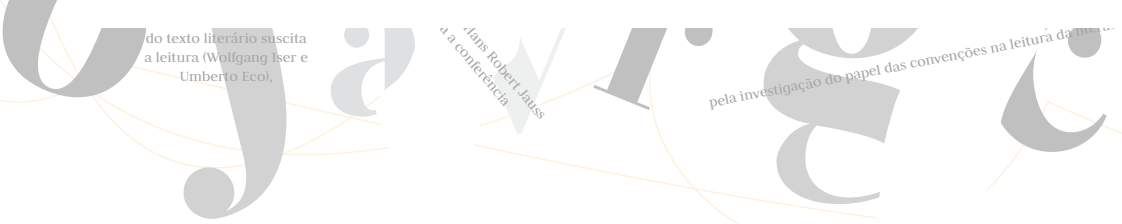
ovo, é necessário tocar o "coração selvagem" da vida com as palavras que jamais poderão substantivá-la e que, no entanto, no furor do espaço artístico, nos acenam com constelações que não constam nos céus: um "septuor” que, assim como o "ovo", não existe: "Como a luz da estrela já morta, o ovo propriamente dito não existe mais" (p. 50).

\section{Referências Bibliográficas}

BLANCHOT, M. O livro por vir. Trad. Leyla Perrone-Moisés. São Paulo: Martins Fontes, 2005. CAMPOS, A. de; CAMPOS, H.; PIGNATARI, D. Mallarmé. São Paulo: Perspectiva, 1974.

CHEVALIER, J.; GHEERBRANT, A.; LAFON, R. Dictionnaire des symboles. Paris: Jupiter, 1982. COMPAGNON, A. O Demônio da teoria: literatura e senso comum. Trad. Cleonice Paes Barreto Mourão. Belo Horizonte: Ed. UFMG, 2002.

LISPECTOR, C. "O ovo e a galinha". In: Felicidade clandestina. Rio de Janeiro: Rocco, 1998. . A paixão segundo G.H. Rio de Janeiro: Rocco, 1998.

MARCHAL, B. Lecture de Mallarmé: Poésies, Igitur, Le coup de dés. Paris: Corti, 1985.

MALLARMÉ, S. Oeuvres complètes. Paris: Gallimard, 2002.

MONDOR, H. Lettre à F. Coppée (5 déc. 1886). In: Vie de Mallarmé. Paris: Gallimard, 1943.

NOULET, E. Vingt poèmes de S. Mallarmé. Genève: Kunding, 1967.

NUNES, B. O drama da linguagem: uma leitura de Clarice Lispector. São Paulo: Ática: 1989. PAZ, O. Commentary on the "Sonnet in yx" of Mallarmé. In: COHN, R. G. (Org.). Mallarmé in the twentieth century. London: Associated University Press, 1988.

PELBART, P. P. Da clausura do fora ao fora da clausura: loucura e desrazão. São Paulo: Brasiliense, 1989.

RICHARD, J.-P. L'univers imaginaire de Mallarmé. Paris: Seuil, 1962.

SISCAR, M. Poesia e crise. Campinas: Ed. Unicamp, 2010.

SYKES, E. Dictionary of non-classical mythology. London: Everyman's, 1953.

ArTigo ReCEBIDO EM: 01 ago. 2012

ArTigo ACEITO EM: 12 set. 2012

ReferênCIA ELETRÔNiCA: GONÇALVES, Vinícius Pacheco. Clarice Lispector e Stéphane Mallarmé: a orquestração do rumor. Revista Criação \& Crítica, n. 9, p. 187-199, nov. 2012. Disponível em: <http://www. revistas.usp.br/criacaoecritica>. Acesso em dd mmm aaaa. 